D

1Pulmonary Institute, Rabin Medical Center, Beilinson Hospital, Petach Tikva, Israel.

${ }^{2}$ Cardiology Division, Veterans Affairs Palo Alto Health Care System/Stanford University,

Palo Alto, CA, USA.

\section{Exercise training in idiopathic pulmonary fibrosis: is it of benefit?}

Exercise is a well-documented safe and effective intervention for prevention and rehabilitation of chronic diseases. Idiopathic pulmonary fibrosis (IPF) is a chronic deadly lung disease associated with severe signs and symptoms, exercise intolerance, diminished quality of life and poor prognosis. In the short term, supervised exercise training programmes have demonstrated clinical benefits in improving exercise capacity, dyspnoea and quality of life in patients with IPF. The underlying mechanisms of chronic adaption to a regular exercise regimen in IPF have yet to be well described and require further investigation. The available data underscore the importance of implementing training principles to target the pathophysiological impairments of IPF in order to optimise training adaption and enhance the outcomes. The current exercise training data in IPF provide sufficient evidence of clinical benefit for consideration to be given to recommending exercise-based pulmonary rehabilitation as standard of care for IPF.

@ERSpublications

An overview of data on exercise for IPF patients, highlighting the importance of exercise training in IPF management http://ow.ly/4mWCCd
Cite as: Vainshelboim B Exercise training in idiopathic pulmonary fibrosis: is it of benefit? Breathe 2016; 12: $130-138$

\section{Introduction}

Exercise training has been widely considered as a safe, effective and powerful behavioural treatment in prevention and rehabilitation medicine [1-3]. Common exercise types involve aerobic, resistance, stretching and balance training. An exercise regimen can improve health-related fitness including cardiorespiratory, muscular strength and endurance, body composition, flexibility and neuromotor components [2]. In healthy adults and chronic disease populations numerous observational and randomised controlled studies have shown significant health benefits in subjects with higher fitness levels and regular exercise and physical activity patterns [1-4]. These benefits include decreased all-cause, cardiovascular and cancer mortality risks, and reduced incidence of coronary arterial disease, several cancer types, stroke, hypertension, type 2 diabetes, obesity, depression, anxiety and falling in the elderly [2-5]. Moreover, improvements in functional health, exercise tolerance, muscle strength and endurance, bone health, cardiometabolic profile, body composition, well-being and cognitive functions are also well documented with increased physical activity levels [3, 4].

Idiopathic pulmonary fibrosis (IPF) is a chronic, progressive and ultimately fatal interstitial lung disease (ILD), occurring primarily in older 
adults [6]. The aetiology is usually unknown, and the unpredictable course of IPF is associated with poor prognosis. Median survival estimates of between 2 and 5 years from the time of diagnosis have been reported [6-8]. Long-term effective treatment, apart from lung transplantation, is still limited for most IPF patients despite some encouraging recent findings using pharmacotherapy [6, 9-11].

IPF is characterised by progressive pulmonary restriction, ventilatory inefficiency, dyspnoea, impaired gas exchange and hypoxaemia, which all lead to diminished exercise capacity $[6,8,12]$. Patients with IPF are more breathless and tend to be less physically active to avoid these symptoms $[13,14]$. All of these manifestations have a significant negative impact on the functional capacity and quality of life (QoL) of IPF patients [8, 12-14]. $A$ recent systematic review demonstrated that short-term exercise training in pulmonary rehabilitation settings is a safe and effective treatment for improving exercise capacity, dyspnoea and QoL in ILD and IPF patients [15]. Here, the role of rehabilitative exercise for patients with IPF is briefly reviewed, highlighting the importance of exercise training in IPF management.

\section{Definitions and terms}

Throughout this review, the Institute of Medicine's and American College of Sports Medicine's terms and definitions are used [1-3]. Physical activity refers to any body movement produced by the contraction of skeletal muscles that causes substantial energy expenditure beyond resting values. Physical fitness refers to a set of measurable health-related or skill-related attributes or characteristics individuals have or achieve that are related to their ability to perform physical activity. Health-related physical fitness includes: cardiorespiratory, muscular strength and endurance, body composition, flexibility and neuromotor components. Exercise refers to planned, structured and repetitive physical activity performed to improve or maintain one or more components of physical fitness [1-3]. Exercise programmes for health purposes in general include several modes such as aerobic, resistance, flexibility, and balance training. Aerobic training is a mode of exercise that involves the body's large muscle groups acting in a dynamic and rhythmic manner for sustained period of time in a continuous or intermittent fashion, for example walking, jogging, cycling, running or swimming [2, 3]. Resistance or strength training is a type of exercise that requires the muscles to work or hold against an applied external force exerted by a machine, weights or body weight. This type of training is implemented in intermittent manner, typically by performing 6-20 repetitions per set followed by rest intervals (0.5-5 min). Each exercise targets specific muscle groups and exercises are commonly performed using groups of $2-4$ sets [3, 16]. Flexibility or stretching exercises are activities designed to preserve or extend the range of motion of the joints [3]. Common static stretching can be performed by holding the muscle at end of its range of motion for 10-30 s, with some degree of discomfort in the stretched muscle [2]. Balance training is a combination of activities designed to improve lower body strength, neuromotor control and agility in order to reduce the likelihood of falling [2, 3].

\section{Pathophysiology of IPF}

Anatomically IPF manifests over several years as structural scar tissue, thickening, collapse and apposition of the alveolar walls, parenchymal damage, and interstitial fibrosis, all of which result in distortion of the normal lung architecture in the absence of known provocation [8, 17]. At rest, IPF patients usually demonstrate the restrictive pulmonary physiology of decreased forced vital capacity and reduced total lung capacity accompanied by severely impaired gas exchange using measures of the diffusion capacity of the lung for carbon monoxide [8, 12]. The resting arterial blood gases are usually normal or may reveal mild hypoxaemia; however, the breathing pattern is often rapid and shallow. In general, as the disease progresses, lung compliance decreases and lung volumes fall [12]. During exercise the limitations are generally multifactorial, including abnormal pulmonary gas exchange, inefficient breathing mechanics, exercise-induced hypoxaemia, circulatory impairments, and respiratory and skeletal muscle dysfunction [12, 18, 19]. A hallmark clinical sign among IPF patients is a decline in arterial oxygen pressure and arterial oxygen saturation $\left(\mathrm{SaO}_{2}\right)$ in response to exercise, which is mainly related to abnormalities in pulmonary gas exchange due to alveolar ventilation/perfusion $\left(V^{\prime} \mathrm{A} / Q^{\prime}\right)$ mismatching, oxygen diffusion limitation and low mixed venous oxygen content [18, 19]. The ventilatory pattern is also abnormal in most IPF patients; however, breathing reserve is usually kept at normal levels [18, 19]. Part of the elevated ventilatory drive in IPF during exercise is related to the increased dead space ventilation $[18,19]$. This increase should raise concerns about pulmonary vascular disease, especially chronic pulmonary emboli or associated emphysema [12]. Dyspnoea is a predominant symptom in IPF and clinically significant due to its strong association with exercise intolerance, poor QoL and mortality [6, 14, 20-22]. Other symptoms such as leg pain, chest discomfort and fatigue are also common reasons for exercise test termination [18, 19]. In addition, patients can often be bothered by a dry cough that interferes with daily activities. The onset of symptoms is slow, but symptoms become progressively worse over time [8]. Exercise intolerance is a cardinal feature of IPF, and is 
associated with severe exertional dyspnoea and fatigue as well as poor QoL [18, 19, 23]. Patients with IPF often exhibit reduced maximal or peak aerobic capacity $\left(V^{\prime} \mathrm{O}_{2}\right.$ peak) and peak work rate, and sub-maximal exercise endurance (anaerobic threshold compared with age- and sex-matched normal subjects) [18].

\section{The why, when, where and what of exercise in IPF}

\section{Why?}

The World Health Organization, the US Centers for Disease and Control Prevention, the American Heart Association and the American College of Sports Medicine state that exercise and physical activity are highly valuable for general health, disease prevention and rehabilitation, and mortality and morbidity risk reduction [1, 3, 4, 24, 25]. The American Thoracic Society and the European Respiratory Society have documented that pulmonary rehabilitation included exercise training is recommended for chronic respiratory diseases other than chronic obstructive pulmonary disease, including ILD and IPF [23]. Furthermore, our team and others have shown significant short-term clinical improvements following supervised exercise training in IPF patients [23, 26-29]. These enhancements seem to have relevant clinical impact in helping IPF patients cope with functional activities of daily life and ameliorating QoL [29]. A recent systematic review concluded that pulmonary rehabilitation is a safe and effective treatment for ILD and IPF patients that enhances exercise capacity and QoL, and reduces dyspnoea immediately after the intervention [15]. Finally, exercise capacity outcomes such as 6-min walking distance (6MWD) and $V^{\prime} \mathrm{O}_{2}$ peak are strong prognostic predictors for mortality in IPF [30-33], and were significantly improved following exercise training interventions with IPF patients [22, $27,29,34-42$ ]. It is possible that improvement in these outcomes after participation in exercise programmes may also have some beneficial effect on prognosis in IPF; however, this has not yet been demonstrated.

\section{When?}

Humans evolved in an environment in which survival obligated physical exertion as a normal behaviour [43]. It is possible that regular exercise and physical activity can have benefits in different stages and conditions of IPF, although research in this area is limited. Several studies demonstrated better adaptation after exercise training programmes in mild-moderate IPF than in more severe IPF conditions [22, 44]. HoLLAND et al. [44] reported a greater improvement in mild disease severity among 25 IPF patients out of a group of
44 ILD patients, based on forced vital capacity, level of desaturation and right ventricle systolic pressure [44]. These results align with the findings of Kozu et al. [22], among 65 IPF patients, demonstrating greater improvement in patients with mild-to-moderate dyspnoea when compared with severe and very severe dyspnoea levels [22]. In contrast, RYERSON et al. [41] showed better pre-rehabilitation functional capacity (as measured by a higher 6MWD) was associated with a lower improvement rate for this outcome in a group of 50 patients with ILD, $41 \%$ of whom were patients with IPF. The current data show some disparity in response and adaptation to exercise training among IPF patients, and future exercise interventions should explore this issue more deeply.

\section{Where?}

Interventional exercise training studies in IPF exhibit variability in the training protocols and research methods used [45]. Although most of the studies were conducted as supervised outpatient-based programmes [22, 27, 29, 35, $37,39-42]$, a few were conducted as home-based $[34,36,46]$, inpatient [38, 46] or combined [22, 46] programmes. Most studies were prospective cohorts [22, 27, 29, 34-36, 39-42, 46], although several were randomised controlled trials [27, 29, 40, 42] and a few were retrospective $[37,38]$. Table 1 illustrates the different programme modalities, the number of IPF subjects included in each study and the degree of improvement based on 6MWD. In general, it seems that supervised exercise training programmes provide robust evidence with over 400 participants and a mean improvement of $50 \mathrm{~m}$ in 6MWD after the interventions. A significantly reduced number of patients completed the home-based and the combined programmes and these interventions were associated with a lower level of improvement, although, currently, there is probably less certainty about generalising these findings. Moreover, considering the signs and symptoms of IPF, especially during physical exertion, perhaps supervised exercise programmes are more appropriate and future research should ascertain this empirically.

Table 1 Exercise programme modalities and the degree of improvement based on 6MWD

\begin{tabular}{lccc}
\hline & $\begin{array}{c}\text { Supervised } \\
\text { programmes }\end{array}$ & $\begin{array}{c}\text { Home-based, } \\
\text { unsupervised } \\
\text { programmes }\end{array}$ & $\begin{array}{c}\text { Combined } \\
\text { programmes }\end{array}$ \\
\hline Reference(s) & {$[27,29,35,37-41]$} & {$[34]$} & {$[22]$} \\
IPF subjects $\mathbf{n}$ & 430 & 17 & 65 \\
Mean $\mathbf{\Delta 6 M W D ~ m}$ & 50 & 40 & 15 \\
\hline
\end{tabular}

6 GMWD: improvement in pre- to post-intervention 6MWD. 


\section{What?}

Exercise training may be challenging to conduct in IPF due to the severe signs and symptoms patients experience, particularly during exercise $[12,18,19]$. Thus understanding of training principles and the pathophysiology of IPF are crucial for successful intervention and outcomes improvement. The majority of exercise training studies in IPF combined aerobic exercise (walking or cycling or both) with resistance and flexibility exercises for peripheral skeletal muscles [22, 27, $29,34,35,37-40,42]$. Some programmes also included respiratory muscle training or breathing exercises [29, 34, 37, 39, 46].

Despite the fact that all these studies reported some improvement in outcomes following the exercise training period, inconsistency still exists with respect to the magnitude of improvement and different measures that have been used across studies [22, 27, 29, 34-42, 46]. Furthermore, most of these studies adopted the established chronic obstructive pulmonary disease guidelines for exercise training in the pulmonary rehabilitation programme. These guidelines might be less appropriate for IPF due to the different pathophysiological mechanisms of exercise limitation, and therefore might not provide optimal exercise stimuli and adaption to training $[23,26]$.
Our group conducted a randomised controlled, supervised exercise training study in 34 IPF patients that demonstrated a meaningful improvement in 6MWD (mean difference between the exercise and control groups: $81 \mathrm{~m}$ ) [29]. Moreover, patients also significantly improved their cardiorespiratory fitness $\left(V^{\prime} \mathrm{O}_{2}\right.$ peak) and aerobic endurance (anaerobic threshold) measured objectively using cardiopulmonary exercise testing [29]. In the exercise programme training principles were implemented to optimise the physiological stimuli and enhance the training adaption for IPF patients [29, 47]. Tables 2 and 3 present outlines of the exercise training programme proposed for IPF [29]. In general, a comprehensive training programme should at least include: aerobic, resistance and flexibility components. Breathing and balance exercises can also be valuable for general health. Further investigation in large randomised controlled studies should address different training modalities to optimise the exercise training programmes for IPF.

\section{Physical activity}

Physical activity has not been extensively studied among patients with IPF; however, in the general population and in chronic respiratory disease

Table 2 Supervised exercise training programme for IPF patients

\begin{tabular}{|c|c|c|c|c|c|}
\hline Phase & Frequency & Type & Time & Intensity & Considerations \\
\hline $\begin{array}{l}\text { Initial } \\
\text { (0-6 weeks) }\end{array}$ & $\begin{array}{l}\text { 2-3 times } \\
\text { a week }\end{array}$ & $\begin{array}{l}\text { Aerobic } \\
\text { Resistance } \\
\text { Flexibility } \\
\text { Breathing }\end{array}$ & $\begin{array}{l}20-40 \mathrm{~min} \\
10-20 \mathrm{~min} \\
10-15 \mathrm{~min} \\
5 \mathrm{~min}\end{array}$ & $\begin{array}{l}50-60 \% \text { of peak } \\
\text { work rate } \\
70-80 \% \text { of average } \\
\text { walking speed on } \\
6 \mathrm{MWT} \\
\text { Borg scale } 3-5\end{array}$ & $\begin{array}{l}\text { Adjust workloads to be tolerable by the patient } \\
\text { Oxygen supplementation for desaturated } \\
\text { patients }\left(\mathrm{SpO}_{2} 85-88 \%\right) \\
\text { Use interval training modality emphasising that } \\
\text { rest periods between exercise bouts allow for } \\
\text { resaturation } \\
\text { Consider reassessment of patients at the end of } \\
6 \text { weeks }\end{array}$ \\
\hline $\begin{array}{l}\text { Improvement } \\
\text { (6 weeks to } \\
6 \text { months) }\end{array}$ & $\begin{array}{l}\text { 2-4 times } \\
\text { a week }\end{array}$ & $\begin{array}{l}\text { Aerobic } \\
\text { Resistance } \\
\text { Flexibility } \\
\text { Breathing }\end{array}$ & $\begin{array}{l}20-50 \mathrm{~min} \\
20-30 \mathrm{~min} \\
10-15 \mathrm{~min} \\
5 \mathrm{~min}\end{array}$ & $\begin{array}{l}60-85 \% \text { of peak } \\
\text { work rate } \\
80-100 \% \text { of average } \\
\text { walking speed on } \\
6 \mathrm{MWT} \\
\text { Borg scale } 4-7\end{array}$ & $\begin{array}{l}\text { Gradually increase time and intensity with } \\
\text { patient tolerance } \\
\text { Oxygen supplementation for desaturated } \\
\text { patients }\left(\mathrm{SpO}_{2} 85-88 \%\right) \\
\text { Use interval training modality emphasising that } \\
\text { rest periods between exercise bouts allow for } \\
\text { resaturation } \\
\text { Consider reassessment of patients at the end of } \\
3 \text { and } 6 \text { months }\end{array}$ \\
\hline $\begin{array}{l}\text { Maintenance } \\
\text { ( } \geq 6 \text { months) }\end{array}$ & $\begin{array}{l}\text { 3-4 times } \\
\text { a week }\end{array}$ & $\begin{array}{l}\text { Aerobic } \\
\text { Resistance } \\
\text { Flexibility } \\
\text { Breathing }\end{array}$ & $\begin{array}{l}20-50 \mathrm{~min} \\
20-30 \mathrm{~min} \\
10-15 \mathrm{~min} \\
5 \mathrm{~min}\end{array}$ & $\begin{array}{l}70-85 \% \text { of peak } \\
\text { work rate } \\
85-100 \% \text { of average } \\
\text { walking speed on } \\
6 \mathrm{MWT} \\
\text { Borg scale } 5-7\end{array}$ & $\begin{array}{l}\text { Maintain the exercise intensity where possible } \\
\text { Oxygen supplementation for desaturated } \\
\text { patients }\left(\mathrm{SpO}_{2} 85-88 \%\right) \\
\text { Use interval modality emphasising that rest } \\
\text { periods between exercise bouts allow for } \\
\text { resaturation } \\
\text { Consider reassessment of patients at } \\
12 \text { months and every } 6 \text { months }\end{array}$ \\
\hline
\end{tabular}

6MWT: 6 min walking test; $\mathrm{SpO}_{2}$ : arterial oxygen saturation measured by pulse oximetry. 
Table 3 Recommended single supervised exercise session for IPF patients

\begin{tabular}{|c|c|c|c|}
\hline $\begin{array}{l}\text { Exercise } \\
\text { component }\end{array}$ & Type & Time & Intensity \\
\hline Warm-up & $\begin{array}{l}\text { Calisthenics } \\
\text { Breathing exercises } \\
\text { Balance exercise }\end{array}$ & $8-10 \min$ & Low to moderate \\
\hline \multirow[t]{2}{*}{$\begin{array}{l}\text { Aerobic } \\
\text { exercise }\end{array}$} & Walking & $\begin{array}{l}(5-10 \text { min walking and } 1 \mathrm{~min} \\
\text { rest }) \times 3=18-33 \text { min }\end{array}$ & $\begin{array}{l}80-90 \% \text { of average } \\
\text { walking speed on } 6 \mathrm{MWT}\end{array}$ \\
\hline & Cycling & $\begin{array}{l}(3-5 \mathrm{~min} \text { cycling and } 1 \mathrm{~min} \\
\text { rest }) \times 3=12-18 \mathrm{~min}\end{array}$ & $60-80 \%$ of peak work rate \\
\hline $\begin{array}{l}\text { Resistance } \\
\text { exercises }\end{array}$ & $\begin{array}{l}\text { Wall push-ups } \\
\text { Chair squats } \\
\text { Dumbbells shoulder press } \\
\text { Supported one-hand rowing } \\
\text { with dumbbell } \\
\text { Dumbbells biceps curl } \\
\text { Dumbbells arm extension } \\
\text { Supported one-leg step-up } \\
\text { Abdominal curl-ups }\end{array}$ & $\begin{array}{l}\text { For each exercise } 1-3 \text { sets of } \\
10-15 \text { repetitions with } 30-60 \mathrm{~s} \\
\text { rest after the set }\end{array}$ & 4-6 on Borg CR 10 scale \\
\hline $\begin{array}{l}\text { Flexibility } \\
\text { exercises }\end{array}$ & $\begin{array}{l}\text { Seated single leg hamstring } \\
\text { stretch } \\
\text { Standing quadriceps stretch, } \\
\text { Chest stretch } \\
\text { Overhead reach stretch } \\
\text { Cat stretch }\end{array}$ & $\begin{array}{l}\text { For each exercise } 1-2 \text { repetitions } \\
\text { of } 15-30 \mathrm{~s} \text { stretch }\end{array}$ & $\begin{array}{l}\text { Muscle discomfort } \\
\text { without severe pain }\end{array}$ \\
\hline
\end{tabular}

Borg CR 10: Borg scale category ratio.

patients inactivity is associated with poorer healthrelated outcomes, including a higher mortality risk $[23,24]$. Using accelerometers for step counting, WALLAERT et al. [48] demonstrated a 65\% lower daily life physical activity level in patients with fibrotic idiopathic interstitial pneumonia (FIIP) compared with healthy sedentary controls. Moreover, this study also showed that, among FIIP patients, physical activity of $<3287$ steps per day was associated with poorer prognosis and an approximately three times higher risk for death (hazard ratio=2.72) [48]. More recently, Nakayama et al. [49] demonstrated that disease severity, as measured by blood biomarkers, the extent of honeycombing measured on computed tomography, 6MWD and dyspnoea levels, was associated with lower physical activity among stable IPF patients. The limited available data on the association between clinical outcomes and physical activity in IPF provide insights into the possibility that physical activity may have a positive effect on prognosis in patients with IPF, and this topic should ascertained in future observational long-term prospective studies.

Supervised exercise and pulmonary rehabilitation programmes are aimed at promoting health-enhancing behaviours, such as physical activity for chronic lung disease patients, but only limited data are available in IPF patients in this area $[23,50]$. Interventional studies evaluating the effect of participating in supervised exercise training or pulmonary rehabilitation programmes on physical activity have consistently shown short-term significant improvement in physical activity levels, but with some contradictions in the follow-up evaluation [41, 51, 52]. While Gaunaurd et al. [51] and Vainshelboim et al. [52], using randomised controlled studies, showed deterioration in physical activity levels at follow-up using the International Physical Activity Questionnaire, RYERSON et al. [41] demonstrated preservation of physical activity based on scores from the Rapid Assessment of Physical Activity questionnaire in prospective noncontrolled study. Due to the importance of promoting physical activity more studies using accurate, objective, electronic instruments are warranted to ascertain the short- and long-term effects of participating in supervised exercise programmes on physical activity levels in IPF patients.

\section{Possible physiological mechanisms of training effect in IPF}

IPF is a complex chronic lung disease that manifests as intra- and extra-pulmonary impairments, which often worsen over time $[6,8,18$, 


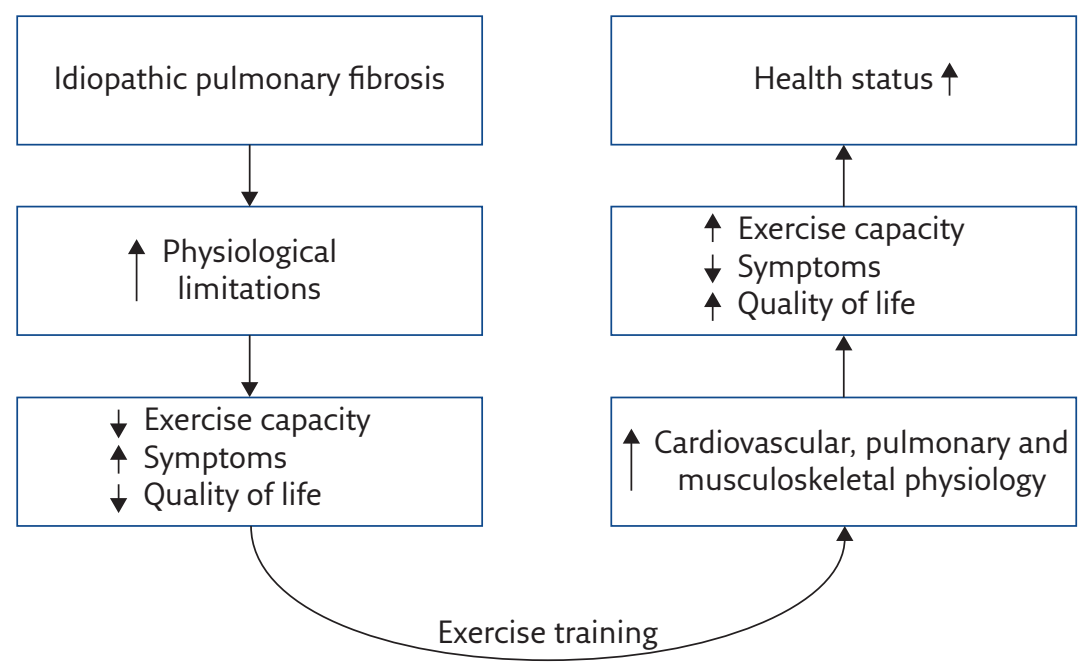

Figure 1 Possible mechanisms for the beneficial effect of exercise training in IPF patients.

19]. Exercise training in healthy subject has been shown to impact on numerous physiological adaptations including the cardiovascular, respiratory and musculoskeletal systems [47]. Chronic appropriate physiological stimulus with exercise may result in beneficial training effects and adaption in patients with IPF despite the existence of significant pathophysiological abnormalities and impairments [3]. Figure 1 illustrates possible mechanisms for the beneficial effect of exercise training in IPF patients.

Our randomised controlled study revealed significant improvement in ventilatory functions after 12 weeks exercise intervention. Furthermore, the improvement in peak tidal volume was significantly correlated $(r=0.78, p=0.001)$ with improvement in $V^{\prime} \mathrm{O}_{2}$ peak values [29]. The underlying mechanism is poorly understood, but may be related to the repetitive stimulus of high ventilatory demand during exercise sessions, chest expansion during deep-breathing exercises and stretching of the thoracic muscles. These may have resulted in a more efficient breathing pattern, improved respiratory muscle strength, enhanced pleural elasticity and pulmonary compliance [12, 18, 26, 29]. This is consistent with a review paper that suggested a beneficial effect of thoracic expansion and stretching on pulmonary restriction in IPF [26]. Most patients in our exercise group also experienced improvements in dyspnoea, which were strengthened by the relationship between exercise and ventilatory capacities and exertional dyspnoea, respectively. The findings are in line with MANALI et al. [53] who reported a significant correlation between the modified Medical Research Council (mMRC) dyspnoea scale and $V^{\prime} \mathrm{O}_{2}$ peak in IPF patients. It is probable that the increase in exercise capacity and ventilatory function resulted in less dyspnoea during sub-maximal exercises such as activities of daily living, which was demonstrated by a decline in $\mathrm{mMRC}$ dyspnoea scale after the programme. This enhancement could have increased alveolar oxygen tension and improved $V^{\prime} \mathrm{A} / Q^{\prime}$ mismatch, resulting in an increase in $V^{\prime} \mathrm{O}_{2}$ peak $[8,12,18]$.

Another training study in 13 ILD patients used near infrared spectroscopy measurements of peripheral oxygen extraction to demonstrate peripheral adaptation after aerobic exercise training, suggesting this as a primary physiological mechanism to aerobic training adaption in ILD [54]. Our group also found a significant improvement after an exercise programme in a cluster of noninvasive exercise cardiovascular indexes representing cardiac power and heart contractility in IPF, which were correlated with improvement in functional capacity (6MWD) (unpublished data). These findings are a novel demonstration of the efficacy of exercise training for exercise cardiovascular function enhancement that could be clinically meaningful for cardiac disease risk reduction and improved prognosis in IPF. Despite the fact that the exact underlying mechanisms of adaption to exercise training in IPF are still not well characterised, data regarding improvements in patient outcomes following exercise training are consistent. Future studies using low-dose computed tomography, stress echocardiography and near infrared spectroscopy should address the intraand extra-pulmonary anatomical and physiological changes following exercise intervention in IPF.

\section{Summary}

Exercise training is a well-established treatment for prevention and rehabilitation chronic conditions. Emerging results provide evidence of the safety and efficacy of exercise training intervention for IPF. Patients completing short-term interventions demonstrated improvements in exercise capacity, dyspnoea and QoL with some benefits in terms of enhancement of leisure physical activity also observed. However, while the benefits of exercise training in IPF patients were consistently demonstrated across the studies, the underlying mechanisms of training adaptation, the optimal programme variables and several other issues still need to be explored in future studies. Finally, considering IPF's pathophysiology, clinical course, limited longterm proven efficient treatments and the robust data of exercise for health benefits, good consideration should be given to recommending supervised exercise training based pulmonary rehabilitation programmes as the standard of care for IPF patients.

\section{Acknowledgements}

The author is grateful to Ricardo Lima (Faculty of Physical Education, University of Brasília, Brasília, Brazil) for his important suggestions in reviewing the manuscript. 


\section{Conflict of interest}

None declared.

\section{References}

1. American College of Sports Medicine. ACSM's guidelines for exercise testing and prescription. 9th edn. Philadelphia, Wolters Kluwer/Lippincott Williams \& Wilkins Health, 2014.

2. Garber CE, Blissmer B, Deschenes MR, et al. American College of Sports Medicine position stand. Quantity and quality of exercise for developing and maintaining cardiorespiratory, musculoskeletal, and neuromotor fitness in apparently healthy adults: guidance for prescribing exercise. Med Sci Sports Exerc 2011; 43: 1334-1359.

3. Chodzko-Zajko WJ, Proctor DN, Fiatarone Singh MA, et al. American College of Sports Medicine position stand. Exercise and physical activity for older adults. Med Sci Sports Exerc 2009; 41: 1510-1530.

4. Nelson ME, Rejeski WJ, Blair SN, et al. Physical activity and public health in older adults: recommendation from the American College of Sports Medicine and the American Heart Association. Circulation 2007; 116: 1094-1105.

5. Bouchard C, Blair SN, Katzmarzyk PT. Less sitting, more physical activity, or higher fitness? Mayo Clin Proc 2015; 90 1533-1540.

6. Raghu G, Collard HR, Egan J, et al. An official ATS/ERS/ JRS/ALAT statement: idiopathic pulmonary fibrosis: evidence-based guidelines for diagnosis and management. Am J Respir Crit Care Med 2011; 183: 788-824.

7. Olson AL, Swigris JJ, Lezotte DC, et al. Mortality from pulmonary fibrosis increased in the United States from 1992 to 2003. Am J Respir Crit Care Med 2007; 176: 277-284.

8. Meltzer EB, Noble PW. Idiopathic pulmonary fibrosis. Orphanet J Rare Dis 2008; 3: 8.

9. King TE Jr, Bradford WZ, Castro-Bernardini S, et al. A phase 3 trial of pirfenidone in patients with idiopathic pulmonary fibrosis. N Engl J Med 2014; 370: 2083-2092.

10. Noble PW, Albera C, Bradford WZ, et al. Pirfenidone in patients with idiopathic pulmonary fibrosis (CAPACITY): two randomised trials. Lancet 2011; 377: 1760-1769.

11. Richeldi L, du Bois RM, Raghu G, et al. Efficacy and safety of nintedanib in idiopathic pulmonary fibrosis. N Engl J Med 2014; 370: 2071-2082.

12. American Thoracic Society. Idiopathic pulmonary fibrosis: diagnosis and treatment. International consensus statement. American Thoracic Society (ATS), and the European Respiratory Society (ERS). Am J Respir Crit Care Med 2000; 161: 646-664.

13. Swigris JJ, Brown KK, Make BJ, et al. Pulmonary rehabilitation in idiopathic pulmonary fibrosis: a call for continued investigation. Respir Med 2008; 102: 1675-1680.

14. Swigris J, Kuschner WG, Jacobs SS, et al. Healthrelated quality of life in patients with idiopathic pulmonary fibrosis: a systematic review. Thorax 2005; 60: 588-594.

15. Dowman L, Hill CJ, Holland AE. Pulmonary rehabilitation for interstitial lung disease. Cochrane Database Syst Rev 2014; 10: CD006322.

16. American College of Sports Medicine. American College of Sports Medicine position stand. Progression models in resistance training for healthy adults. Med Sci Sports Exerc 2009; 41: 687-708.

17. Fukuda Y, Basset F, Ferrans VJ, et al. Significance of early intra-alveolar fibrotic lesions and integrin expression in lung biopsy specimens from patients with idiopathic pulmonary fibrosis. Hum Pathol 1995; 26: 53-61.

18. Lama VN, Martinez FJ. Resting and exercise physiology in interstitial lung diseases. Clin Chest Med 2004; 25 435-453.

19. Holland AE. Exercise limitation in interstitial lung disease - mechanisms, significance and therapeutic options. Chron Respir Dis 2010; 7: 101-111.
20. Ryerson CJ, Donesky D, Pantilat SZ, et al. Dyspnea in idiopathic pulmonary fibrosis: a systematic review. J Pain Symptom Manage 2012; 43: 771-782.

21. Mura M, Porretta MA, Bargagli E, et al. Predicting survival in newly diagnosed idiopathic pulmonary fibrosis: a 3-year prospective study. Eur Respir J 2012; 40: 101-109.

22. Kozu R, Jenkins S, Senjyu H. Effect of disability level on response to pulmonary rehabilitation in patients with idiopathic pulmonary fibrosis. Respirology 2011; 16: 11961202.

23. Spruit MA, Singh SJ, Garvey C, et al. An official American Thoracic Society/European Respiratory Society statement: key concepts and advances in pulmonary rehabilitation. Am J Respir Crit Care Med 2013; 188: e13-e64.

24. World Health Organization. Global Recommendations on Physical Activity for Health. Geneva, WHO Press, 2010.

25. Pate RR, Pratt M, Blair SN, et al. Physical activity and public health. A recommendation from the Centers for Disease Control and Prevention and the American College of Sports Medicine. JAMA 1995; 273: 402-407.

26. Kenn K, Gloeckl R, Behr J. Pulmonary rehabilitation in patients with idiopathic pulmonary fibrosis-a review. Respiration 2013; 86: 89-99.

27. Nishiyama $\mathrm{O}$, Kondoh $\mathrm{Y}$, Kimura $\mathrm{T}$, et al. Effects of pulmonary rehabilitation in patients with idiopathic pulmonary fibrosis. Respirology 2008; 13: 394-399.

28. Holland A, Hill C. Physical training for interstitial lung disease. Cochrane Database Syst Rev 2008; 4: CD006322.

29. Vainshelboim B, Oliveira J, Yehoshua L, et al. Exercise training-based pulmonary rehabilitation program is clinically beneficial for idiopathic pulmonary fibrosis. Respiration 2014; 88: 378-388.

30. du Bois RM, Albera C, Bradford WZ, et al. 6-Minute walk distance is an independent predictor of mortality in patients with idiopathic pulmonary fibrosis. Eur Respir J 2014; 43: 1421-1429.

31. Fell CD, Liu LX, Motika C, et al. The prognostic value of cardiopulmonary exercise testing in idiopathic pulmonary fibrosis. Am J Respir Crit Care Med 2009; 179: 402-407.

32. Caminati A, Bianchi A, Cassandro R, et al. Walking distance on 6-MWT is a prognostic factor in idiopathic pulmonary fibrosis. Respir Med 2009; 103: 117-123.

33. Lederer DJ, Arcasoy SM, Wilt JS, et al. Six-minutewalk distance predicts waiting list survival in idiopathic pulmonary fibrosis. Am J Respir Crit Care Med 2006; 174: 659-664.

34. Ozalevli S, Karaali HK, Ilgin D, et al. Effect of homebased pulmonary rehabilitation in patients with idiopathic pulmonary fibrosis. Multidiscip Respir Med 2010; 5: 31-37.

35. Swigris JJ, Fairclough DL, Morrison M, et al. Beneficial effects of pulmonary rehabilitation in idiopathic pulmonary fibrosis. Respir Care 2011; 56: 783-789.

36. Rammaert B, Leroy S, Cavestri B, et al. Home-based pulmonary rehabilitation in idiopathic pulmonary fibrosis. Rev Mal Respir 2011; 28: e52-e57.

37. Ferreira A, Garvey C, Connors GL, et al. Pulmonary rehabilitation in interstitial lung disease: benefits and predictors of response. Chest 2009; 135: 442-447.

38. Huppmann P, Sczepanski B, Boensch M, et al. Effects of inpatient pulmonary rehabilitation in patients with interstitial lung disease. Eur RespirJ 2013; 42: 444-453.

39. Arizono S, Taniguchi $\mathrm{H}$, Sakamoto $\mathrm{K}$, et al. Endurance time is the most responsive exercise measurement in idiopathic pulmonary fibrosis. Respir Care 2014; 59: 1108-1115. 
40. Holland AE, Hill CJ, Conron M, et al. Short term improvement in exercise capacity and symptoms following exercise training in interstitial lung disease. Thorax 2008; 63: 549-554.

41. Ryerson CJ, Cayou C, Topp F, et al. Pulmonary rehabilitation improves long-term outcomes in interstitial lung disease: a prospective cohort study. Respir Med 2014; 108: 203-210.

42. Jackson RM, Gómez-Marin OW, Ramos CF, et al. Exercise limitation in IPF patients: a randomized trial of pulmonary rehabilitation. Lung 2014; 192: 367-376.

43. Archer E, Blair SN. Physical activity and the prevention of cardiovascular disease: from evolution to epidemiology. Prog Cardiovasc Dis 2011; 53: 387-396.

44. Holland AE, Hill CJ, Glaspole I, et al. Predictors of benefit following pulmonary rehabilitation for interstitial lung disease. Respir Med 2012; 106: 429-435.

45. Vainshelboim B, Fox BD, Oliveira J, et al. Exercise training in idiopathic pulmonary fibrosis. Expert Rev Respir Med 2016; 10: 69-77.

46. Jastrzebski D, Gumola A, Gawlik R, et al. Dyspnea and quality of life in patients with pulmonary fibrosis after six weeks of respiratory rehabilitation. J Physiol Pharmacol 2006; 57: Suppl., 139-148.

47. Kenney WL, Wilmore JH, Costill DL. Physiology of sport and exercise. 5th Edn. Champaign, Human Kinetics, 2012.

48. Wallaert B, Monge E, Le Rouzic O, et al. Physical activity in daily life of patients with fibrotic idiopathic interstitial pneumonia. Chest 2013; 144: 1652-1658.
49. Nakayama M, Bando M, Araki K, et al. Physical activity in patients with idiopathic pulmonary fibrosis. Respirology 2015; 20: 640-646.

50. Nici L, Donner C, Wouters E, et al. American Thoracic Society/European Respiratory Society statement on pulmonary rehabilitation. Am J Respir Crit Care Med 2006; 173: 1390-1413.

51. Gaunaurd IA, Gómez-Marín OW, Ramos CF, et al. Physical activity and quality of life improvements of patients with idiopathic pulmonary fibrosis completing a pulmonary rehabilitation program. Respir Care 2014; 59: 1872-1879.

52. Vainshelboim B, Fox BD, Kramer MR, et al. Shortterm improvement in physical activity and body composition after supervised exercise training program in idiopathic pulmonary fibrosis. Arch Phys Med Rehabil 2016 [in press; DOI: 10.1016/j.apmr.2016.01.018]

53. Manali ED, Lyberopoulos P, Triantafillidou C, et al. MRC chronic dyspnea scale: relationships with cardiopulmonary exercise testing and 6-minute walk test in idiopathic pulmonary fibrosis patients: a prospective study. BMC Pulm Med 2010; 10: 32.

54. Keyser RE, Woolstenhulme JG, Chin LM, et al. Cardiorespiratory function before and after aerobic exercise training in patients with interstitial lung disease. J Cardiopulm Rehabil Prev 2015; 35: 47-55. 